\title{
Long-term Stable NIR-SWIR Photodetector Driven by Photothermal Effect of Polypyrrole Nanostructures
}

Hengyang Xiang, ${ }^{1,2}$ Chenghao Xin, ${ }^{2}$ Zhelu Hu, ${ }^{2}{ }^{*}$ Lionel Aigouy, ${ }^{2}$ Zhuoying Chen ${ }^{2} *$ and Xiaojiao

$\operatorname{Yuan}^{3, *}$

${ }^{1}$ MIIT Key Laboratory of Advanced Display Materials and Devices, Institute of Optoelectronics \&

Nanomaterials, College of Materials Science and Engineering, Nanjing University of Science and

Technology, Nanjing 210094, China

${ }^{2}$ LPEM, ESPCI Paris, PSL Research University, Sorbonne Université, CNRS, 10 Rue Vauquelin,

F-75005 Paris, France

${ }^{3}$ Institut de Chimie Physique, UMR 8000 CNRS, Université Paris-Saclay, 91405 Orsay, France

* Corresponding authors. E-mail addresses: hu.zhelu@espci.fr; zhuoying.chen@espci.fr;

yxjxjks@126.com

KEYWORDS: polypyrrole nanostructures, photothermal effect, solution-process, long-term stability,

broadband photodetection

\begin{abstract}
Polypyrrole (PPy) is a conductive polymer and widely applied in different applications owing to its broadband absorption in the UV-visible, near-infrared (NIR) and short-wave-infrared (SWIR) spectrum, excellent conductivity and strong photothermal effect. In this work, we explored for the first time the photothermal effect of polypyrrole nanoparticles (PPy-NPs) in a photothermal-induced detector structure, and developed a new type of air-stable hybrid PPy-NPs/Pt photodetector (PD) with NIR/SWIR sensitivity. By combining PPy-NPs with a platinum (Pt) resistive pattern, we fabricated PPy-NPs/Pt PDs that are sensitive to illumination in the wavelength range from $800 \mathrm{~nm}$ to $2000 \mathrm{~nm}$. Under the illumination of $\lambda=1.5 \mu \mathrm{m}$, the maximum photoresponsivity was measured to be $\sim 1.3 \mathrm{~A} / \mathrm{W}$ with a $131 \mu$ s photoresponse rise time. Owing to the material stability from both PPy-NPs and the Pt pattern, the current photodetectors show long-term stable photoresponsivity when they were stored in air without encapsulation. The results suggest that the PPy-NPs/Pt hybrid
\end{abstract}


PDs are promising candidates for a new type of low-cost and broadband due to their multiple advantages such as free of toxic heavy-metals, air stability and solution-processing.

\section{Introduction}

Short-wave infrared (SWIR) detectors have attracted much attention because they can be used in various applications such as night vision, light detection and ranging, biological imaging, etc. ${ }^{1-4}$ Current detectors can be mainly classified into either photon type photodetectors or thermal type photodetectors depending on their underlying functional mechanisms. Most state-of-the-art SWIR photodetectors are photon detectors, which typically rely on narrow band gap semiconductors (such as $\mathrm{Ge},{ }^{5} \mathrm{PbS},{ }^{6} \mathrm{InGaAs}^{7}{ }^{\mathrm{InSb}}{ }^{8}$ ), and are expensive (epitaxial growth requirement) and/or environmental unfriendly. To circumvent these disadvantages, SWIR-absorbing solution-processed plasmonic gold (Au) nanoparticles have been recently proposed as a promising candidate to apply on thermal detectors for SWIR photodetection due to their remarkable plasmonic-induced photothermal effect. ${ }^{9-11}$ For example, under the illumination of a $\lambda=1.5 \mu \mathrm{m}$ laser, hybrid photodetectors based on plasmonic Au nanorods (NRs) and its photothermal effect applied on a platinum microwire exhibited a maximum photoresponsivity of $4500 \Omega / \mathrm{W}$ (in terms of resistance change $(\Delta \mathrm{R})$ over illumination power $(\mathrm{P})$ ) or $340 \mathrm{~mA} / \mathrm{W}$ (in terms of $\Delta \mathrm{t} / \mathrm{P}$ ). ${ }^{10}$ While these initial demonstrations are highly encouraging, for applications, it would be highly desirable to further improve the responsivity of such devices.

One strategy to increase the photoresponsivity of thermal SWIR detectors is to apply alternative materials with stronger photothermal effect. Herein, we propose the application of polypyrrole nanoparticles (PPy-NPs) ${ }^{12-15}$ in a thermal photodetector structure for near-infrared (NIR) and SWIR photodetection. Polypyrrole (PPy) is a conductive polymer which has been intensively investigated during the last decades. ${ }^{16-18}$ Due to its broadband absorption in the UV-Vis and NIR/SWIR spectrum, excellent conductivity and photothermal effect, PPy-NPs have been applied for photocatalysis, ${ }^{19,20}$ supercapacitor electrodes, ${ }^{21,22}$ photothermal therapy (PTT) ${ }^{23-26}$ and biomedical imaging. ${ }^{25,27-29}$ For example in PTT application, ${ }^{30-33}$ while both plasmonic Au-NRs and PPy-NPs can exhibit strong photothermal effect, the synthesis of PPy-NPs does not require costly noble metal elements. More interestingly, in photothermal cancer ablation studies, a stronger photothermal effect was observed on PPy-NPs than Au-NRs under equal mass concentration. ${ }^{15}$ These previous studies suggest PPy-NPs have great potential to be applied in a thermal detector structure for photodetection. While the photoconductivity of PPy-NPs has been used for photodetection, ${ }^{34,35}$ the strong photothermal effect of PPy-NPs is another alternative candidate for thermal (photo)detectors. ${ }^{36}$ In a recent report by Yang et

al., ${ }^{36}$ the photothermal effect of PPy-NPs was applied on thermochromic crystals, which achieved photosensitivity to NIR by observing the intensity of the absorption spectrum from a spectrometer. Furthermore, the reaction time of such devices (which is inversely proportional to material/device light sensitivity) is no shorter than a few seconds.

Here, we successfully demonstrate the use of solution-processed PPy-NPs and their photothermal effect to achieve broadband $(\lambda=800 \mathrm{~nm}-2000 \mathrm{~nm})$ photodetection. The synthesized PPy-NPs are deposited onto a platinum (Pt) pattern to form a hybrid PPy-NPs/Pt device, which achieved a high responsivity of $\sim 1.3 \mathrm{~A} / \mathrm{W}$ (or $7.5 \times 10^{6} \Omega / \mathrm{W}$ in terms of $\Delta \mathrm{R} / \mathrm{P}$ ) at $\lambda=1.5 \mu \mathrm{m}$. In addition, we followed 
the device characteristics over storage time and found that PPy-NPs/Pt photodetectors are highly stable in the atmospheric environment even without encapsulation. This work shows that PPy-NPs are bright nanomaterials capable to provide broadband photodetection in NIR and SWIR spectra owing to its excellent photothermal effect, together with heavy-metal-free and stable-in-ambient characteristics.

\section{Results and Discussion}

a
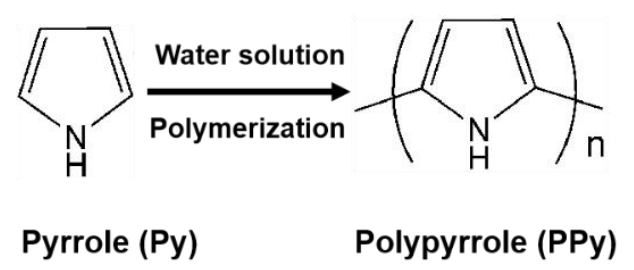

C

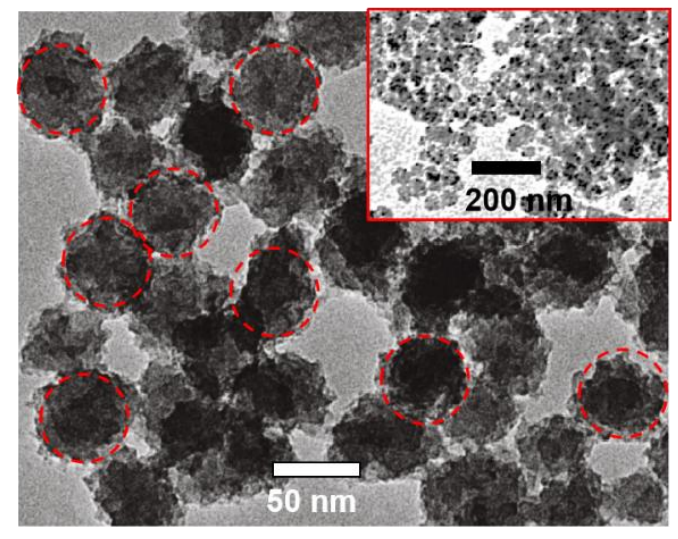

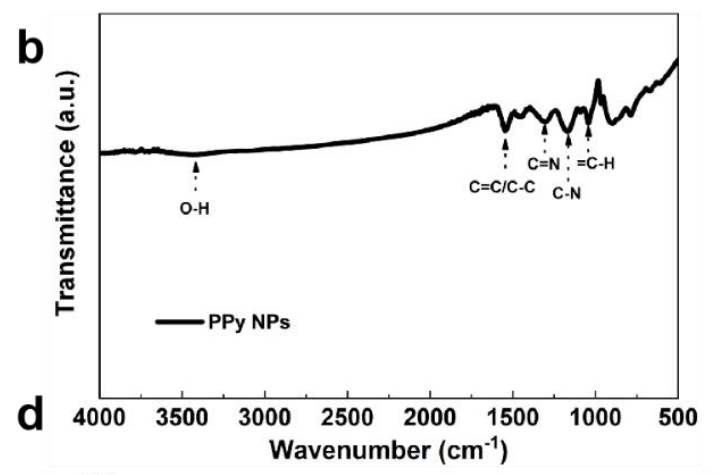

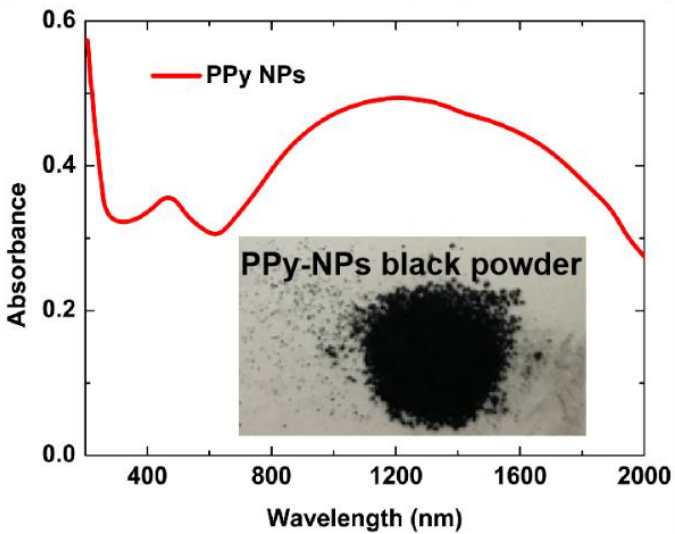

Figure 1. (a) PPy polymerization by chemical oxidation; (b) FTIR spectra of the PPy-NPs with their characteristic IR peaks; (c) Transmission Electron Microscopy (TEM) image of PPy-NPs, the insert is a zoom-out TEM image for many PPy-NPs; (d) Absorption spectrum of PPy-NPs (insert image is the picture of the PPy-NPs black powder).

PPy-NPs were synthesized in soft templates which are produced by self-assembly of surfactants in a quaternary system (water, oil, surfactant and cosurfactant, chemical structure and polymerization process of PPy-NPs is shown in Figure 1a). ${ }^{19}$ These PPy-NPs' structural characteristics are confirmed by Fourier-transform infrared spectroscopy (FTIR) and X-ray diffraction (XRD), as shown in Figure 1b and Figure S1, respectively, consistent with previous literature reports. ${ }^{37,38}$ The obtained PPy-NPs exhibit a uniform particle size of $50 \mathrm{~nm}$ in diameter (Figure 1c). The synthesized PPy-NPs are black powder, exhibiting a broadband optical absorption spectrum covering UV, visible and NIR/SWIR range (Figure 1d). Especially for the wavelength range of $800 \mathrm{~nm}$ to $2000 \mathrm{~nm}$, PPy-NPs exhibit significant photon absorption suggesting their potential as a photosensitive material for NIR-SWIR photodetection. 

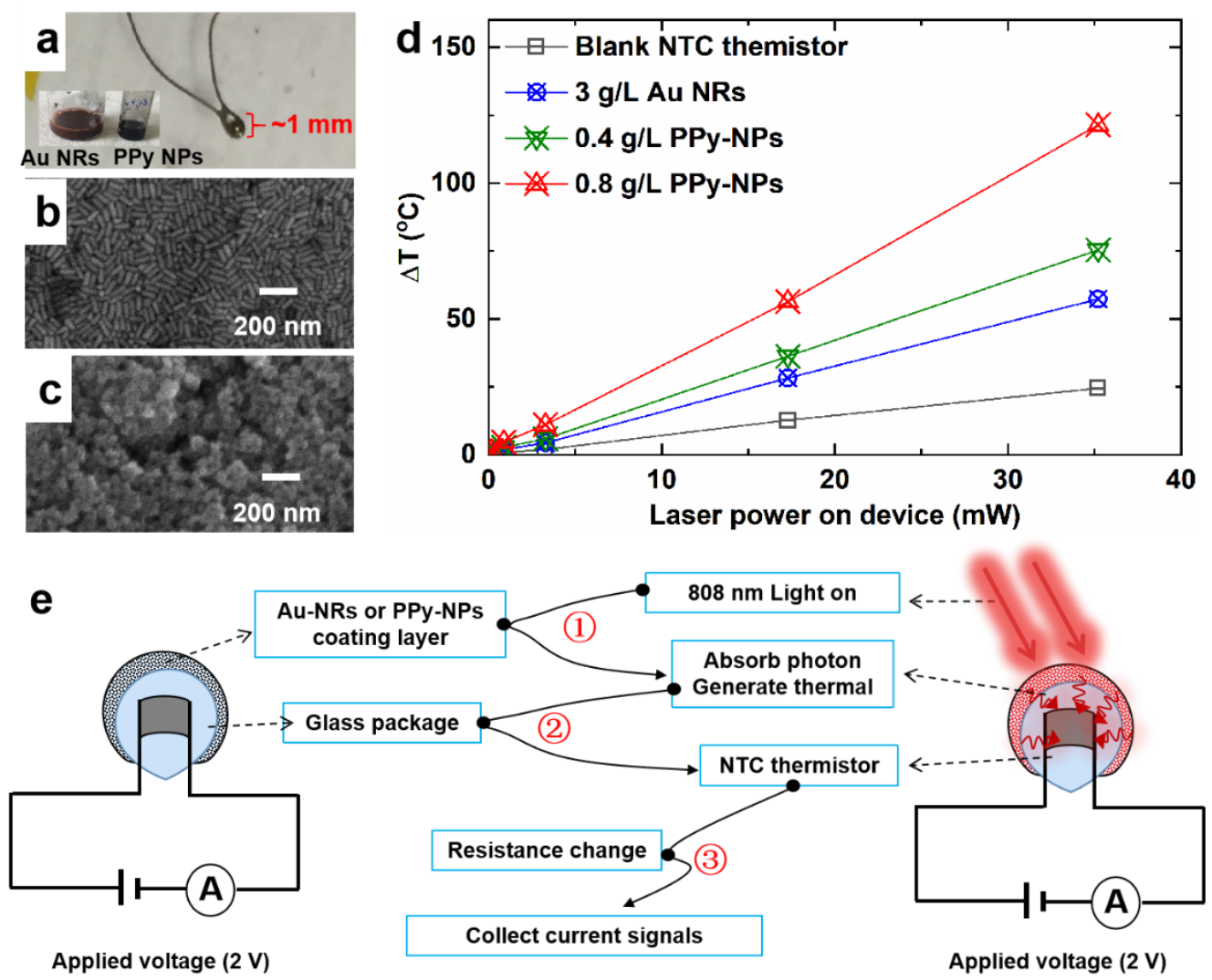

Figure 2. (a) A negative temperature coefficient (NTC) thermistor with PPy-NPs coating, the size of NTC thermistor is $\sim 1 \mathrm{~mm}$. The PPy-NPs water solution and Au-NRs water solution were shown in the insert picture. SEM image of Au-NRs (b) and PPy-NPs (c). The temperature change $(\Delta T)$ as the function of laser power on the devices measured on each type of NPs decorated NTC-thermistors by comparison to the control device (without NPs) (d). (e) Device structure diagram and working process (Step 1, 2, 3) of the hybrid device with Au-NRs or PPy-NPs.

Figure 2a presents the optical image of a commercial negative temperature coefficient (NTC) thermistor, by which we harvest the photo-induced heat of PPy-NPs. To confirm the photothermal effect of PPy-NPs and compare it with Au-NRs, we drop-coated an aqueous solution of PPy-NPs and an aqueous solution of Au-NRs onto NTC thermistors to form Au-NRs/thermistor PD and PPy-NPs/thermistor PD, respectively. Several layers of Au-NRs and PPy-NPs are deposited on the surface of NTC thermistor (Figure 2b-2c). The absorption spectrum of PPy-NPs solution (Figure 1c) and Au-NRs solution (Figure S2) show that they have a strong photon harvest capability around 800 $\mathrm{nm}$. Therefore, a $\lambda=808 \mathrm{~nm}$ laser was illuminated on the NTC thermistor and hybrid devices to act as an external heat source. In these devices, NTC thermistors are sensitive to changes in ambient temperature, and detection of it will cause its resistance to change. For this typical NTC thermistor, the relationship between its resistance and temperature has been calibrated (Figure S3). Under the illumination of the $\lambda=808 \mathrm{~nm}$ laser at different powers, different temperatures were then measured on $\mathrm{Au}$ or PPy-NPs/NTC-thermistor hybrid devices by comparison to the control device (blank NTC thermistor without NPs) (Figure 2d). For the blank NTC thermistor, when the laser power increases 
from $0.03 \mathrm{~mW}$ to $35.2 \mathrm{~mW}$ (power density increases from $3.75 \mathrm{~mW} / \mathrm{cm}^{2}$ to $4400 \mathrm{~mW} / \mathrm{cm}^{2}$ ), the temperature rise owing to the direct heating of the laser itself. In contrast, when a certain concentration of Au-NRs (3 g/L) or PPy-NPs $(0.4 \mathrm{~g} / \mathrm{L})$ was coated onto the NTC thermistor, thanks to the photothermal effect of the NRs/NPs, a much higher temperature value can be obtained under the same laser power. Moreover, compared with the Au-NR solution for the Au-NRs/thermistor devices, even a a lower weight concentration PPy-NPs solution after dilution can be used to fabricate the PPy-NPs/thermistor devices and obtain higher temperature value at a fixed laser power. At the optimal concentration of PPy-NPs (0.8 g/L), the temperature of the PPy-NPs/thermistor device increases from room temperature (without laser) to $125{ }^{\circ} \mathrm{C}$ (under laser illumination at $35.2 \mathrm{~mW}$ ), which is twice higher than that of $0.4 \mathrm{~g} / \mathrm{L}$ PPy-NPs/thermistor device and 2.5 times higher than the measured value of $3 \mathrm{~g} / \mathrm{L} \mathrm{Au}-\mathrm{NRs} /$ thermistor device (concentration optimization process was shown in Figure S4). From these results, it can be observed that PPy-NPs, even with a lower mass concentration applied, exhibit a stronger photothermal effect than plasmonic Au-NRs. This strong photothermal effect has been attributed to the electron phonon interactions in PPy-NPs, ${ }^{39}$ resulting in a much higher photothermal conversion efficiency of $34.3 \%$, which is much better than that of Au-NRs (Calculation detail for photothermal conversion efficiency is described in Equation S1, S2 and Figure S5). These results demonstrate the PPy-NPs' outstanding photothermal conversion ability, which is consistent with previous research. ${ }^{15}$ In terms of device design, although hybrid NPs/thermistor photodetectors based on plasmonic Au-NRs have been implemented in the past, ${ }^{9}$ such hybrid photodetectors have not been demonstrated with PPy-NPs. Figure 2e shows the different steps involved in the function of such hybrid devices. Firstly, PPy-NPs absorb photons from the $\lambda=808 \mathrm{~nm}$ laser due to the polaronic transitions. ${ }^{40,41}$ Secondly, due to the strong electron phonon interactions, heat is generated and diffuses to the NTC thermistor in direct contact with PPy-NPs (Step 2). Finally, in Step 3, the temperature rise of the NTC thermistor leads to a change of its resistance, which is measurable by an external circuit with an applied voltage of $2 \mathrm{~V}$.

Under an external DC bias of $2 \mathrm{~V}$, due to a change of resistance under monochromatic illumination, current changes can be measured at each wavelength (current changes at some typical wavelengths were shown in Figure 3a, 3b), so that the presence of NIR and SWIR light (800 nm - $2000 \mathrm{~nm})$ can be detected. The light power on device at this wavelength window varied from $1.3 \mu \mathrm{W}$ (at $2000 \mathrm{~nm}$ ) to $2.8 \mu \mathrm{W}$ (at $1300 \mathrm{~nm}$ ). Figure 3c presents the photoresponsivity of the hybrid PPy-NPs/thermistor device under these monochromatic wavelengths irradiation. The black symbols in Figure 3c show the photodetection capability (photoresponsivity) of this type of PPy-NPs/thermistor hybrid device, plotted in terms of $\Delta \mathrm{R} / \mathrm{P}(\Omega / \mathrm{W})$, where $\Delta \mathrm{R}$ is the resistance change $(\Omega)$ and $\mathrm{P}$ is the incident light power $(\mathrm{W})$ on the device at each monochromatic wavelength. With a fixed external applied DC voltage $(2 \mathrm{~V})$, the measured photoresponsivity can also be plotted as $\Delta \mathrm{I} / \mathrm{P}(\mathrm{A} / \mathrm{W})$, where $\Delta \mathrm{I}$ is the current change under illumination (red symbols in Figure 3c). In the wavelength range from $800 \mathrm{~nm}$ to $2000 \mathrm{~nm}$, a photoresponsivity ranging from $0.5 \mathrm{~A} / \mathrm{W}$ to $1.3 \mathrm{~A} / \mathrm{W}$ was measured in the current PPy-NPs/thermistor hybrid device, which is comparable to the results obtained on commercial InGaAs PDs. ${ }^{42}$ Besides monochromatic illumination with relatively low power density, two lasers with wavelengths of $808 \mathrm{~nm}$ and $1.5 \mu \mathrm{m}$ laser operated at different powers were also applied separately as 
illumination source to the hybrid device (Figure 3d). A clear rise and drop of the measured current was associated with the on and off of the laser.
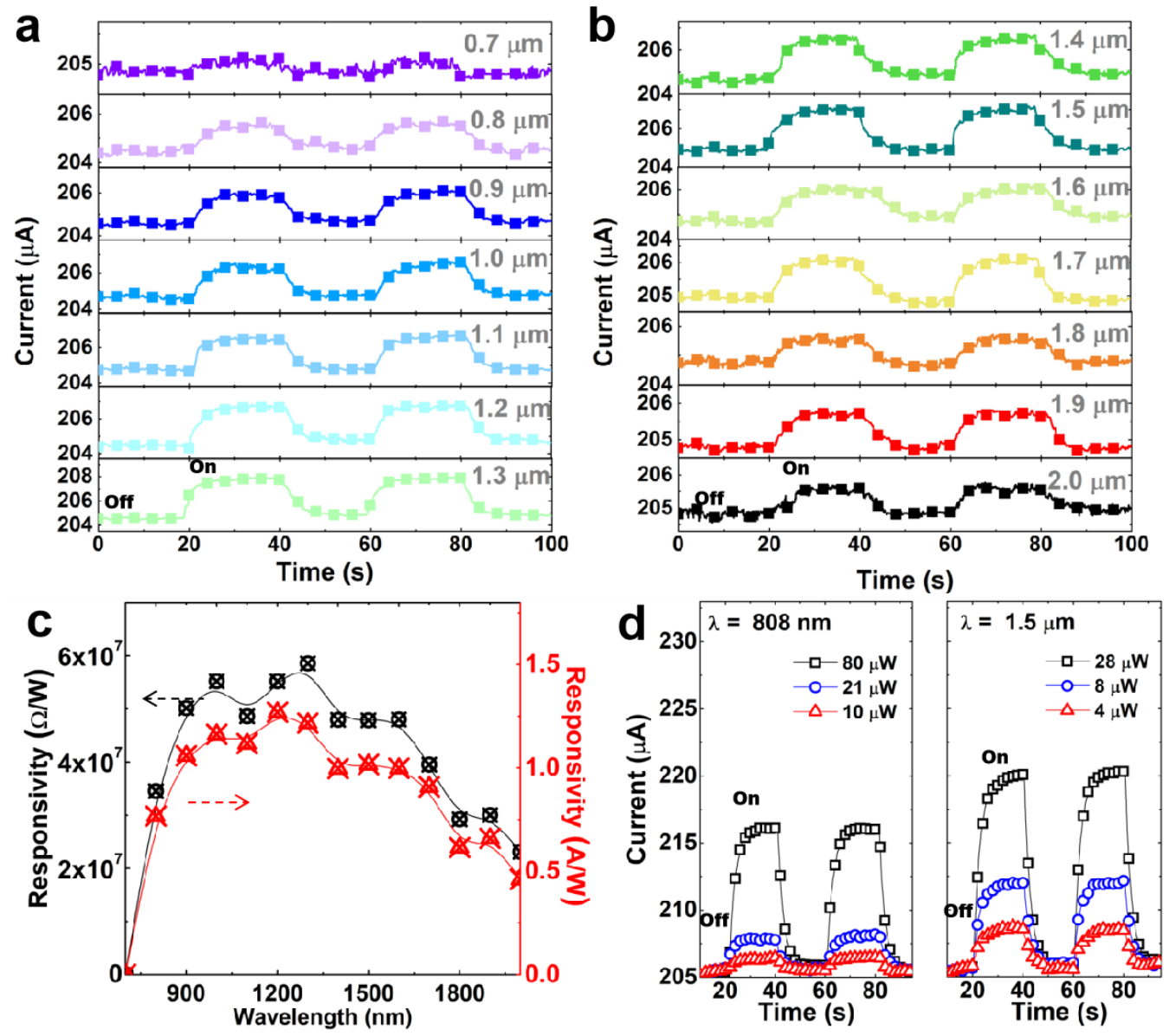

Figure 3. (a-b) Photoresponse characteristics over time of a hybrid PPy-NPs/thermistor device in the form of photo-induced current changing upon exposure of monochromatic illumination ( $\lambda$ from 0.8 $\mu \mathrm{m}$ to $2.0 \mu \mathrm{m}$ ). The current was measured under an external applied DC voltage of $2 \mathrm{~V}$. (c) The photoresponsivity (in $\Omega / \mathrm{W}$ or in $\mathrm{A} / \mathrm{W}$ ) as a function of the whole wavelength window tested $(800 \mathrm{~nm}$ $2000 \mathrm{~nm}$ ). (d) Photoresponse characteristics over time as a function of laser power under $808 \mathrm{~nm}$ laser and $1.5 \mu \mathrm{m}$ laser.

For photodetection applications, besides the photoresponsivity, the photoresponse time (T) is also a key parameter to determine the scope of potential applications. $\mathrm{T}$ is usually defined as the time needed for the photoresponse to rise to $80 \%$ of its maximum value under illumination, e.g. from $10 \%$ to $90 \%$ or from $0 \%$ to $80 \%$. In the above-mentioned PPy-NPs/thermistor device, it is likely due to the inefficient heat diffusion from the NPs to the glass package and then to the thermistor, the rise time was very modest (about $2 \mathrm{~s}$ ). In order to improve this aspect, here, we designed and fabricated platinum (Pt) patterns ${ }^{10,43}$ to harvest the photothermal effect of PPy-NPs. In this hybrid PPy-NPs/Pt photodetector, $3 \mu \mathrm{L}$ of PPy-NPs solution was deposited directly onto the Pt pattern which was defined 
on a glass substrate (Figure 4a). After the solvent was dried, PPy-NPs were then evenly coated on the Pt pattern, as indicated by the SEM image in Figure 4a. The left insert of Figure 4a zooms in the morphology of PPy-NPs on the Pt pattern, the right insert shows a schematic diagram of the device operation briefly (Device structure in details is shown in Figure S6 and S7). To characterize such hybrid PDs, a $\lambda=1.5 \mu \mathrm{m}$ laser was focused onto this device with its ON/OFF modulated by a function generator. As shown in Figure $\mathbf{4 b}$, a clear illumination-induced resistance change was recorded at different power levels. Figure $\mathbf{4} \mathbf{c}$ shows the ON/OFF modulation of the hybrid PPy-NPs/Pt device under laser illumination as a rise/fall curve of $120 \mathrm{~Hz}$ light response, in which the response time of $131 \mu$ s rise and $203 \mu$ s fall is measured. By comparing with the above-mentioned PPy-NPs/thermistor devices, the response time of the PPy-NPs/Pt hybrid PDs here is shortened by 6 orders of magnitude. A strong photoresponsivity (in $\Omega / \mathrm{W}$ and $\mathrm{A} / \mathrm{W}$ ) was measured, and the maximum value reached $7.5 \times 10^{6} \Omega / \mathrm{W}$ and $1.3 \mathrm{~A} / \mathrm{W}$ (Figure 4d). Detectivity ( $\mathrm{D}^{*}$ ), as another key parameter to evaluate the performance of PDs, was also calculated by following some reference equations from previous studies. $^{44,45}$ The maximum $\mathrm{D}^{*}$ for our PPy-NPs/Pt device can reach $1.1 * 10^{11}$ Jones, which is comparable with some InGaAs PDs $\left(D^{*}=1 * 10^{10}-1 * 10^{13}\right.$ Jones) and nanostructured PDs $\left(D^{*}=\right.$ $1 * 10^{8}-1 * 10^{14}$ Jones). ${ }^{46-48}$ Compared with commercial $\mathrm{PDs}^{46,48}$ and some nanoparticle-based ones $^{10,49-52}$, this PPy-NPs/Pt hybrid PD is competitive in photodetection range, responsivity and response time, as summarized in Table 1. Notably, PPy-NPs/Pt hybrid PD reveals both faster photoresponse and slightly larger photoresponsivity than PPy-NPs/thermistor PD, although the size of Pt pattern is much smaller than that of NTC thermistor. It means that a smaller and simpler Pt pattern structure helps to improve both photoresponsivity and response time even if the number of PPy-NPs is not very large. As we described in Figure 2e and Figure 4a, during the detection process, the thermal diffusion capacity of the device plays an important role, involving the thermal diffusivity $(\alpha)$ and thermal resistance $\left(\mathrm{R}_{\theta}\right)$, as shown in Equation (1) and (2), respectively. Thermal diffusivity, $\alpha$, is determined by the thermal conductivity $(\mathrm{k})$, density $(\rho)$ and specific heat capacity $(\mathrm{C})$ of the heat transfer surroundings/materials. In our devices, the heat transfer surroundings are mainly the glass package $\left(\mathrm{k}=1.1 \mathrm{~W} \cdot \mathrm{m}^{-1} \cdot \mathrm{K}^{-1}, \rho=2.2 \mathrm{~g} \cdot \mathrm{cm}^{-3}, \mathrm{C}=840 \mathrm{~J} \cdot \mathrm{kg}^{-1} \cdot \mathrm{K}^{-1}\right)$ for PPy-NPs/thermistor PD and the Pt pattern $\left(\mathrm{k}=70 \mathrm{~W} \cdot \mathrm{m}^{-1} \cdot \mathrm{K}^{-1}, \rho=21.45 \mathrm{~g} \cdot \mathrm{cm}^{-3}, \mathrm{C}=135 \mathrm{~J} \cdot \mathrm{kg}^{-1} \cdot \mathrm{K}^{-1}\right)$ for PPy-NPs/Pt PD. By the equation 1 , the $\alpha$ value of $2.4^{*} 10^{-5} \mathrm{~m}^{2} \cdot \mathrm{s}^{-1}$ and $5.9 * 10^{-7} \mathrm{~m}^{2} \cdot \mathrm{s}^{-1}$ was calculated, respectively, showing that the Pt has much better thermal diffusion rate, which contributed to the shorter response time in PPy-NPs/Pt PD. When it comes to thermal resistance $\left(\mathrm{R}_{\theta}\right)$, e.g. in a PPy-NPs/Pt PD with the determined parameters of $\mathrm{k}$ and cross-sectional area (A), the size of the Pt pattern ( $\Delta \mathrm{x}$ in the equation 2$)$ will be the key parameter, smaller size will be easier for the thermal to diffuse and reach a balance.

$$
\begin{gathered}
\alpha=\frac{\mathrm{k}}{\rho \cdot \mathrm{C}} \\
\mathrm{R}_{\theta}=\frac{\Delta \mathrm{x}}{\mathrm{k} \cdot \mathrm{A}}
\end{gathered}
$$



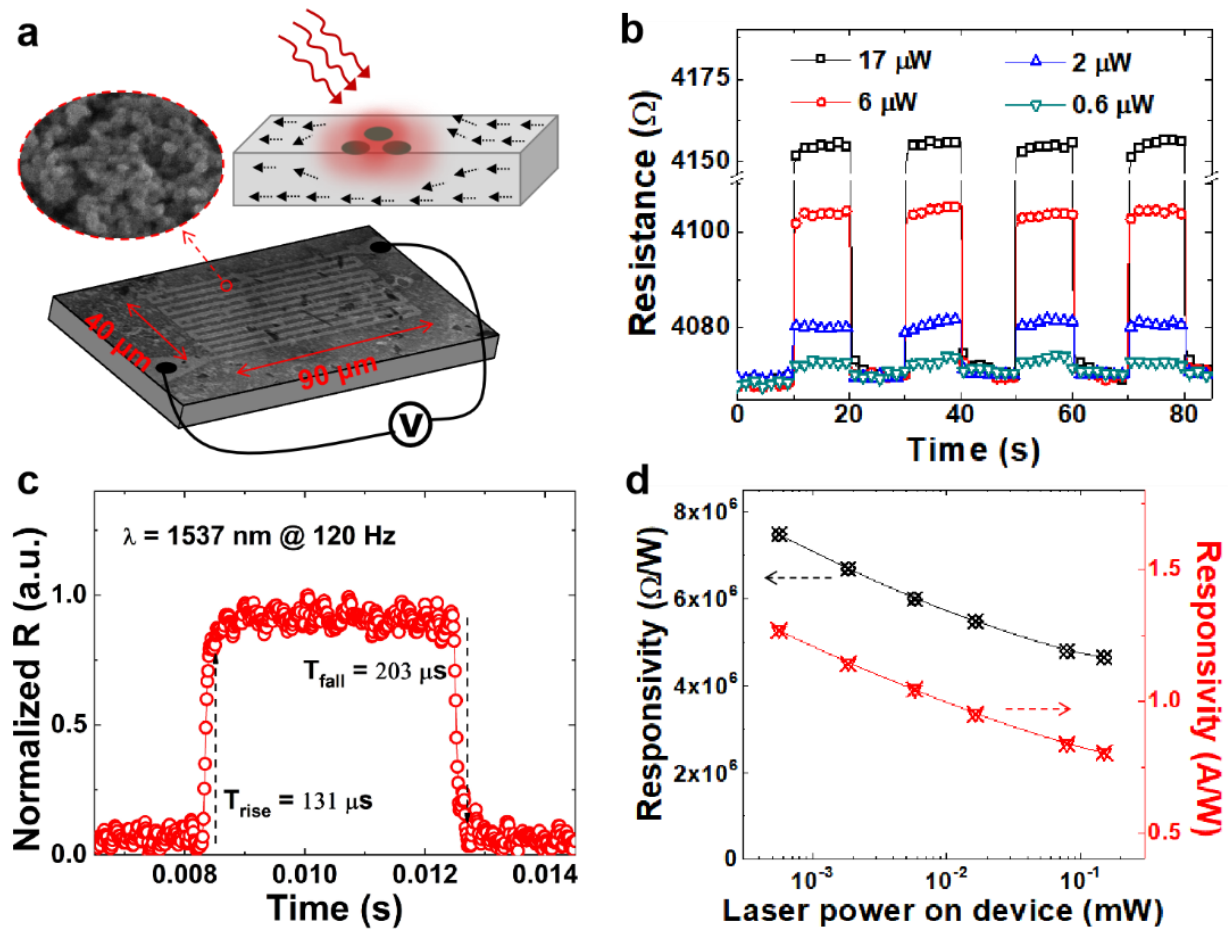

Figure 4. (a) SEM image of the hybrid PPy-NPs/Pt photodetector, the left insert is the morphology of PPy-NPs on the Pt pattern, the right insert shows a schematic diagram of the device operation briefly. (b) Photoinduced resistance change over time as the function of laser power $(\lambda=1.5 \mu \mathrm{m})$ with a laser ON/OFF modulation frequency. (c) Response time of the PPy-NPs/Pt device measured under the $\lambda=$ $1.5 \mu \mathrm{m}$ laser modulated at $120 \mathrm{~Hz}$. Rise time $\left(\mathrm{T}_{\text {rise }}\right)$ is the normalized resistance $(\mathrm{R})$ rising from 0 to $80 \%$, fall time $\left(\mathrm{T}_{\text {fall }}\right)$ is the normalized $\mathrm{R}$ falling from $100 \%$ to $20 \%$. (d) The photoresponsivity (in $\Omega / \mathrm{W}$ or in $\mathrm{A} / \mathrm{W}$ ) as a function of laser power from $1.5 \mu \mathrm{m}$ laser.

Table 1. Summary of photodetection range, responsivity and response time in commercial PDs and some nanoparticle-based ones.

\begin{tabular}{|c|c|c|c|c|}
\hline Materials & $\begin{array}{c}\text { Response } \\
\text { range }(\mathbf{n m})\end{array}$ & $\begin{array}{c}\text { Peak } \\
\text { responsivity }\end{array}$ & $\begin{array}{l}\text { Response time } \\
\left(\mathbf{T}_{\text {rise }} / \mathbf{T}_{\text {fall }}\right)\end{array}$ & Ref. \\
\hline Commercial Si PD & $400-1100$ & $\begin{array}{l}0.5 \mathrm{~A} / \mathrm{W} @ 780 \\
\mathrm{~nm}\end{array}$ & $<1 \mathrm{~ns} /<1 \mathrm{~ns}$ & 48 \\
\hline Commercial InGaAs PD & $800-1700$ & 1 A/W@ 1300 & $<1 \mathrm{~ns} /<1 \mathrm{~ns}$ & 46 \\
\hline Au-NRs/ZnO-nanowire & $650-850$ & - & $0.25 \mathrm{~s} / 0.69 \mathrm{~s}$ & 49 \\
\hline
\end{tabular}




\begin{tabular}{|c|c|c|c|c|c|}
\hline $\mathrm{Au}-\mathrm{NPs} / \mathrm{TiO}_{2}$ & $400-900$ & $\begin{array}{l}0.5 \mathrm{~mA} / \mathrm{W} \\
600 \mathrm{~nm}\end{array}$ & @ & $1.5 \mathrm{~s} / 1.5 \mathrm{~s}$ & 51 \\
\hline $\mathrm{SiO}_{2}$-AuNRs/SLG-InP & $300-1200$ & $\begin{array}{l}0.14 \quad \mathrm{~A} / \mathrm{W} \\
980 \mathrm{~nm}\end{array}$ & @ & $441 \mathrm{~ns} / 443 \mathrm{~ns}$ & 50 \\
\hline $\mathrm{Au}-\mathrm{PbS}$ core-shell NPs & $405-1064$ & $\begin{array}{l}18.5 \quad \mathrm{~A} / \mathrm{W} \\
980 \mathrm{~nm}\end{array}$ & @ & $0.32 \mathrm{~s} / 0.25 \mathrm{~s}$ & 52 \\
\hline Au-NRs/Pt-microwire & 1540 & $\begin{array}{l}340 \mathrm{~mA} / \mathrm{W} \\
1540 \mathrm{~nm}\end{array}$ & @ & $97 \mu \mathrm{s} / 170 \mu \mathrm{s}$ & 10 \\
\hline PPy-NPs/Pt-micropattern & $800-2000$ & $\begin{array}{l}1.3 \mathrm{~A} / \mathrm{W} \\
1200 \mathrm{~nm}\end{array}$ & @ & $130 \mu \mathrm{s} / 203 \mu \mathrm{s}$ & $\begin{array}{l}\text { This } \\
\text { work }\end{array}$ \\
\hline
\end{tabular}

In addition to the high-performance photodetection capability, the current PPy-NPs/Pt hybrid PDs exhibited an excellent stability in air and a wide processing window. For example, PPy-NPs can be dispersed and stored in various solvents, such as water, ethanol and acetone. Figure 5a shows the absorption spectra of PPy-NPs dispersed in different solvents (water, ethanol, acetone) after heating at $60{ }^{\circ} \mathrm{C}$ for $6 \mathrm{~h}$. No significant changes in the optical absorption were observed in these heated solutions by comparison to freshly synthesized PPy-NPs dispersed in water. Thanks to the excellent stability of PPy-NPs, the obtained PPy-NPs/Pt hybrid PDs exhibited long-term device stability when stored in air. A comparative experiment was carried out on PPy-NPs/Pt hybrid PD by comparing with Au-NRs/Pt PD (Figure 5b). The two hybrid devices were stored in air for 6 months without any encapsulation. On Au-NRs/Pt device, a rapid decline in photoresponsivity was observed within the first month of storage owing to the fusion and regrowth of $\mathrm{Au}-\mathrm{NRs}$ inherent in the high surface energy of $\mathrm{Au}$ nanoparticles. These morphology changes were observed in the inserted SEM images in Figure 5b. During a 3-month device storage, the Au-NRs continued to age and fuse into large micron-sized particles, which resulted in the loss of their plasmonic absorption characteristics in the NIR and SWIR spectrum. By comparison, confirmed by SEM on samples over different air storage times, the PPy-NPs morphology are highly stable. As a result, after a 6-month device storage, the PPy-NPs/Pt device still maintained photoresponsivity, which was equivalent to more than $90 \%$ of the photoresponsivity measured on fresh device. The samples were confirmed by SEM under different air storage times, and the morphology of PPy-NPs was still almost identical to that observed in fresh samples. In order to further confirm the molecular structure of the PPy-NPs after six months of months in air exposure, their IR spectra was recorded by the FTIR. The characteristic IR peaks remained completely consistent with the initial sample (Figure S8), proving the outstanding stability of the PPy-NPs. 
a

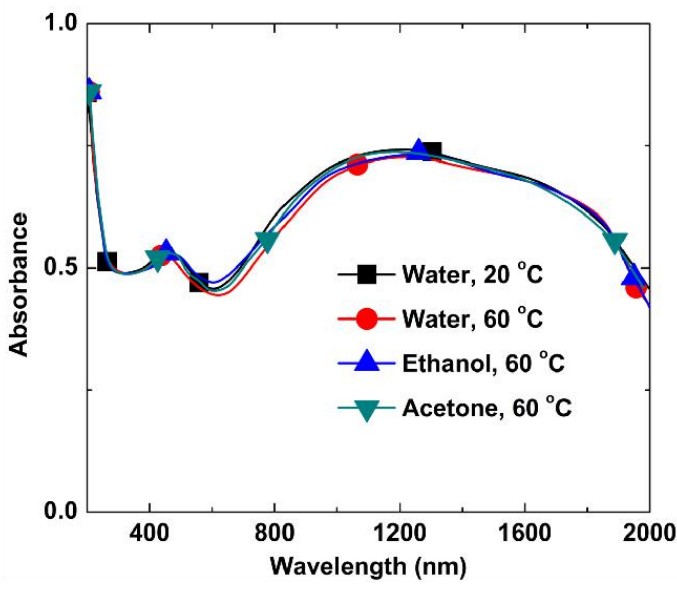

b

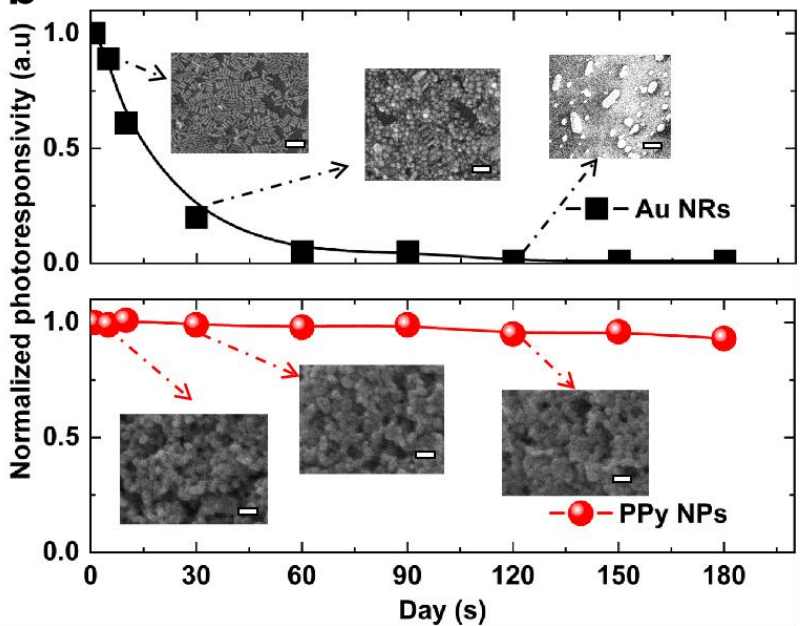

Figure 5. (a) Absorption spectrum of PPy-NPs in different solvents (water, ethanol, acetone) and temperature $\left(20{ }^{\circ} \mathrm{C}\right.$ and $\left.60{ }^{\circ} \mathrm{C}\right)$. (b) Long-term device stability test of PPy-NPs/Pt device and $\mathrm{Au}-\mathrm{NRs} / \mathrm{Pt}$ device, which are exposed to the atmosphere without packaging. The insert pictures are the SEM images of Au-NRs or PPy-NPs on the Pt pattern during the test (Scale bar is $200 \mathrm{~nm}$ ).

\section{Conclusion}

In summary, we successfully demonstrated the strong photothermal effect of PPy-NPs in the thermal photodetector structure, and developed an air-stabilized hybrid NPs/Pt photodetector (PD) with photoresponsivity in the NIR/SWIR spectrum window $(800 \mathrm{~nm}-2000 \mathrm{~nm})$. Hybrid PPy-NPs/thermistor and PPy-NPs/Pt devices were fabricated and characterized. On PPy-NPs/Pt PD, we demonstrated a fast response time of $131 \mu$ s and a high photoresponsivity of $1.3 \mathrm{~A} / \mathrm{W}\left(@ \mathrm{~V}_{\text {applied }}=\right.$ $2 \mathrm{~V}$ ) under $\lambda=1.5 \mu \mathrm{m}$ laser illumination. The PPy-NPs/Pt PDs have a wide processing window due to the excellent stability of PPy-NPs in various solvents. The resulting PPy-NPs/Pt PDs are air stable even without encapsulation, and maintain $>90 \%$ photoresponsivity after a 6-month air storage period. These results indicate that PPy-NPs/Pt PD is a competitive candidate for next generation of low-cost and toxic-heavy-metal-free NIR/SWIR photodetectors.

\section{Experimental section}

\section{Synthesis of PPy-NPs}

PPy-NPs were synthesized by chemical oxidation of the Py monomer confined in the oil phase of hexagonal mesophases $(0.1 \mathrm{mM})$. Hexagonal mesophases are made of a mixture of sodium dodecyl sulfate (SDS) as surfactant, salted water phase $(\mathrm{NaCl})$, cyclohexane as oil phase and pentanol as co-surfactant. The experimental details are as follow: $100 \mu \mathrm{L}$ Py was added to $4 \mathrm{~mL}$ of an aqueous 
solution containing $0.1 \mathrm{M} \mathrm{NaCl}$, and $1.6 \mathrm{~g}$ SDS were introduced to the obtained solution. A transparent viscous micellar solution (solution $\mathrm{A}$ ) was obtained after vortexed and heat $\left(50{ }^{\circ} \mathrm{C}\right.$ for $1 \mathrm{~h}$ ). $0.1 \mathrm{M} \mathrm{FeCl}_{3}$ (as oxidant) was dissolved in $4 \mathrm{~mL}$ of water and then $1.6 \mathrm{~g}$ SDS was introduced in the solution, solution B can be obtained by vortexed and heat at $50{ }^{\circ} \mathrm{C}$ for $1 \mathrm{~h}$. Subsequently, $6 \mathrm{~mL}$ of cyclohexane and $400 \mu \mathrm{L}$ n-pentanol (co-surfactant) were added dropwise to each micellar. The mixtures were then vortexed until a transparent and yellow translucent, birefringent gels (hexagonal mesophases) were obtained. Mixing A and B lead to a black gel. A black powder PPy-NPs was then obtained after cleaned and dried.

\section{Synthesis of Au-NRs}

Colloidal Au-NRs used in this work were synthesized by following previously described methods ${ }^{9,53}$.

Au nanoparticle seed solution: After mixing $5 \mathrm{ml}$ of $0.5 \mathrm{mM} \mathrm{HAuCl}_{4}$ solution with $5 \mathrm{ml}$ of $0.2 \mathrm{M}$ CTAB solution, $1 \mathrm{ml}$ of $0.006 \mathrm{M} \mathrm{NaBH}_{4}$ solution was added followed by vigorously stirring for 2 minutes. This solution was then aged for 30 minutes without stirring.

Au-NR growth solution: CTAB ( $7 \mathrm{~g})$ was evenly mixed with NaOL $(1.234 \mathrm{~g})$, and then dissolved it in $250 \mathrm{ml}$ de-ionized (DI) water under stirring at $50{ }^{\circ} \mathrm{C}$. After cooling the solution to $30{ }^{\circ} \mathrm{C}, 20 \mathrm{ml}$ of 4.15 $\mathrm{mM} \mathrm{AgNO}_{3}$ solution is added into the system, keeping the whole solution at $30{ }^{\circ} \mathrm{C}$ for 15 minutes. This is followed by the addition of $250 \mathrm{ml}$ of $1 \mathrm{mM} \mathrm{HAuCl}_{4}$ solution with stirring for about 90 minutes (until the solution became colorless). At this stage, $1.6 \mathrm{ml}$ of $12.1 \mathrm{M} \mathrm{HCl}$ solution was added under stirring for 15 minutes. $1.25 \mathrm{ml}$ of $0.064 \mathrm{M}$ ascorbic acid solution was then added under vigorous stirring for 30s. Finally, $0.4 \mathrm{ml}$ seed solution was added under rigorous stirring for $30 \mathrm{~s}$, and then the whole solution was kept at $30{ }^{\circ} \mathrm{C}$ for 12 hours without stirring to maintain the NR growth. After 12 hours of growth, the final product was separated by centrifugation (6k rpm for 30 minutes) and subsequent decantation of the mother liquid. DI water was then added to re-dissolve the Au-NRs. The centrifugation/decantation process was repeated for 3 times and the final Au-NR products were dissolved in DI water.

\section{NTC-thermistor based devices fabrication and measurement}

Hybrid devices involving NTC thermistors was fabricated by the following procedure: In brief, a drop $(\approx 3 \mu \mathrm{L}$ ) of Au-NRs (with a concentration of $3 \mathrm{~g} / \mathrm{L}$ ) or PPy-NPs (with a concentration of $0.4 \mathrm{~g} / \mathrm{L}$ and $0.8 \mathrm{~g} / \mathrm{L}$ ) in water was casted directly to coat the surface of the thermistor. After the solvent (water) was dried on the thermistor, the hybrid devices were measured under monochromatic illumination generated by a quartz halogen lamp and a computer-controlled Oriel Cornerstone monochromator (and appropriate order sorting filters). The intensity of the monochromatic illumination was calibrated by a National Institute of Standards and Technology-calibrated germanium photodiode. The monochromatic illumination was modulated by a shutter while the resistance of the hybrid and control device was measured by a computer-controlled Keithley 2634B source measurement unit (SMU). Concerning measurements under laser, the output of a fiber-coupled laser diode $(\lambda=808 \mathrm{~nm})$ was

focused onto the devices. The diameter of the laser spot is about $1 \mathrm{~mm}$, which can almost cover the 
entire device. Neutral density filters were used to adjust the laser power, while the laser power was calibrated by a laser power meter. The laser illumination was modulated by a shutter, while the photothermal induced current and resistance was measured by a Keithley 2634B SMU. From the data sheet of the thermistor, each resistance value measured corresponds to a temperature value. When the illumination was on (or off), a resistance value of $\mathrm{R}_{\text {light-on }}$ (or $\mathrm{R}_{\text {light-off }}$ ) was measured and a current value of $\mathrm{I}_{\text {light-on }}$ (or $\mathrm{I}_{\text {light-off }}$ ) can also be measured (under an external DC voltage bias of $2 \mathrm{~V}$ ). From $\mathrm{R}_{\text {light-on }}$ (or $\mathrm{R}_{\text {light-off }}$ ) and the datasheet provided by the manufactory of the thermistor, the temperature value ( $\mathrm{T}_{\text {light-on }}$ or $\mathrm{T}_{\text {light-off }}$ ) corresponding to the resistance value can be obtained. From $\mathrm{T}_{\text {light-on }}$ and $\mathrm{T}_{\text {light-off }}$, the temperature change $\left(\mathrm{T}_{\text {light-on }}-\mathrm{T}_{\text {light-off }}\right)$ of the hybrid device due to the illumination was obtained.

\section{Pt-based device fabrication and measurement}

A layer of adherence promoter (TI from microchemicals) and a layer of photosensitive resin (AZ5214, microchemicals) were spin-coated layer by layer on cleaned glass substrates. Pt pattern was then defined by direct laser writing lithography (Heidelberg Ins. laserwriter $\mu$ PG101). After lithography, substrates were developed by dipping the sample in a bath of developer (AZ726 MIF, microchemicals) for $30 \mathrm{~s}$ with subsequent DI water rising and air-drying. The $\mathrm{Ti}(5 \mathrm{~nm}) / \mathrm{Pt}(40 \mathrm{~nm})$ layer was then evaporated onto the sample by an e-beam evaporator (Plassys MEB550S). Finally, the Pt-coated substrates were lifted-off by immersing the samples into a bath of acetone. To fabricate the hybrid PPy-NPs/Pt PDs, PPy-NPs water solution was deposited onto the Pt pattern at an optimized concentration of $0.8 \mathrm{~g} / \mathrm{L}$. Finally, solvent was allowed to dry in air.

To characterize the photoresponse of PPy-NPs/Pt PDs, a Fabry-Perot pigtailed laser (peak $\lambda=1537$ $\mathrm{nm}$ ) was focused onto the Pt/Au-NRs device. The diameter of the laser spot is about $150 \mu \mathrm{m}$, which was focused by an extra lens. The light spot can cover the whole Pt pattern zone (90 $\mu \mathrm{m} * 40 \mu \mathrm{m})$. To characterize the response speed, the device was placed in a series circuit with an applied voltage of $2 \mathrm{~V}$. During the measurements, the laser spot was modulated by a functional generator (Aim-TTi TG1006) with a laser $\mathrm{ON} / \mathrm{OFF}$ frequency of $120 \mathrm{~Hz}$. The resistance changes $(\Delta \mathrm{R})$ of the Au-NR/Pt device was measured in the same circuit $($ Bias $=2 \mathrm{~V})$. To verify the broadband photoresponsivity of the device, the testing conditions under a monochromatic light source was identical to the description above on NPs/thermistor PDs. For the resistance/current responsivity measurements, neutral density filters were used to adjust the laser power, while the laser power was calibrated by a laser power meter. The laser illumination was modulated by a shutter, while the photothermal induced current and resistance was measured by a Keithley 2634B SMU identical to the description above on NPs/thermistor PDs.

\section{Optical and morphology characterizations}

UV-Visible absorption spectra were measured in the air by an Agilent 5E UV-Visible-NIR spectrometer. TEM characterizations were performed with a JEOL 2010 microscope operating at 200 $\mathrm{kV}$. SEM characterizations were performed by the FEI Magellan 400 system with a field emission gun 
electron source. FTIR (Fourier Transform Infrared) spectroscopy were measured by a Bruker Alpha-II FTTIR spectrometer.

\section{ASSOCIATED CONTENT}

\section{Supporting Information.}

The Supporting Information is available free of charge on the ACS Publications website.

Additional results on XRD of PPy-NPs; Absorption spectrum of Au-NRs solution; Relationship between resistance and temperature in NTC thermistors; Concentration optimization process of the PPy-NPs/NTC-thermistor; Photothermal conversion efficiency calculation details; Device structure of the hybrid PPy-NPs/Pt photodetector; FTIR spectra of the PPy-NPs with their characteristic IR peaks. (PDF)

\section{AUTHOR INFORMATION}

\section{Corresponding Author}

* Corresponding authors. E-mail addresses: E-mail: hu.zhelu@espci.fr; zhuoying.chen@espci.fr; yxjxjks@126.com

\section{Author Contributions}

The manuscript was written through contributions of all authors. All authors have given approval to the final version of the manuscript.

\section{Notes}

The authors declare no competing financial interest.

\section{ACKNOWLEDGMENT}

H.X., X.Y. and Z.H. acknowledge the China scholarship council (CSC) for Ph.D. thesis scholarship. H.X. acknowledge the National Natural Science Foundation of China (62004101), the Fundamental Research Funds for the Central Universities (30920041117), the China Postdoctoral Science Foundation (2020M681600). SEM characterizations performed were supported by the region Île-de-France in the framework of DIM Nano-K.

\section{Reference}

(1) Pradhan, S.; Dalmases, M.; Konstantatos, G. Solid-State Thin-Film Broadband Short-Wave Infrared Light Emitters. Adv. Mater. 2020, 32 (45), 1-6. https://doi.org/10.1002/adma.202003830. 
(2) Sicard, M.; Thome, K. J.; Crowther, B. G.; Smith, M. W. Shortwave Infrared Spectroradiometer for Atmospheric Transmittance Measurements. J. Atmos. Ocean. Technol. 1998, 15 (1), 174-183. https://doi.org/10.1175/1520-0426(1998)015<0174:SISFAT>2.0.CO;2.

Hong, G.; Antaris, A. L.; Dai, H. Near-Infrared Fluorophores for Biomedical Imaging. Nat. Biomed. Eng. 2017, 1 (1), 0010. https://doi.org/10.1038/s41551-016-0010.

(4) Hansen, M. P.; Malchow, D. S. Overview of SWIR Detectors, Cameras, and Applications. In Proc.SPIE; 2008; Vol. 6939, p 69390I.

Xu, Q.; Hu, J.; Wang, X. On-Chip Ge, InGaAs, and Colloidal Quantum Dot Photodetectors: Comparisons for Application in Silicon Photonics. J. Opt. Soc. Am. B 2021, 38 (1), 194. https://doi.org/10.1364/josab.403604.

(6) Saran, R.; Curry, R. J. Lead Sulphide Nanocrystal Photodetector Technologies. Nat. Photonics 2016, 10 (2), 81. https://doi.org/10.1038/nphoton.2015.280.

(7) Geum, D. M.; Kim, S. K.; Lee, S.; Lim, D.; Kim, H. J.; Choi, C. H.; Kim, S. H. Monolithic 3D Integration of InGaAs Photodetectors on Si MOSFETs Using Sequential Fabrication Process. IEEE Electron Device Lett. 2020, 41 (3), 433-436. https://doi.org/10.1109/LED.2020.2966986.

Zhang, S.; Jiao, H.; Wang, X.; Chen, Y.; Wang, H.; Zhu, L.; Jiang, W.; Liu, J.; Sun, L.; Lin, T.;

Shen, H.; Hu, W.; Meng, X.; Pan, D.; Wang, J.; Zhao, J.; Chu, J. Highly Sensitive InSb Nanosheets Infrared Photodetector Passivated by Ferroelectric Polymer. Adv. Funct. Mater. 2020, 30 (51), 2006156. https://doi.org/10.1002/adfm.202006156.

(9) Xiang, H.; Niu, T.; Schoenauer Sebag, M.; Hu, Z.; Xu, X.; Billot, L.; Aigouy, L.; Chen, Z. Short-Wave Infrared Sensor by the Photothermal Effect of Colloidal Gold Nanorods. Small 2018, 14 (16), 1704013. https://doi.org/10.1002/smll.201704013.

(10) Xiang, H.; Hu, Z.; Billot, L.; Aigouy, L.; Chen, Z. Hybrid Plasmonic Gold-Nanorod-Platinum Short-Wave Infrared Photodetectors with Fast Response. Nanoscale 2019, 11 (39), 18124-18131. https://doi.org/10.1039/C9NR04792A.

(11) Xiang, H.; Lin, H.-J.; Niu, T.; Chen, Z.; Aigouy, L. Nanoscale Thermal Characterization of High Aspect Ratio Gold Nanorods for Photothermal Applications at $\lambda=1.5 \mu$ M. J. Appl. Phys. 2019, 125 (16), 163101. https://doi.org/10.1063/1.5088944.

(12) Shi, G.; Rouabhia, M.; Wang, Z.; Dao, L. H.; Zhang, Z. A Novel Electrically Conductive and Biodegradable Composite Made of Polypyrrole Nanoparticles and Polylactide. Biomaterials 2004, 25 (13), 2477-2488. https://doi.org/10.1016/j.biomaterials.2003.09.032.

(13) Wang, H.; Lin, T.; Kaynak, A. Polypyrrole Nanoparticles and Dye Absorption Properties. Synth. Met. 2005, 151 (2), 136-140. https://doi.org/10.1016/j.synthmet.2005.03.020.

(14) Wu, J.; Li, Q.; Fan, L.; Lan, Z.; Li, P.; Lin, J.; Hao, S. High-Performance Polypyrrole Nanoparticles Counter Electrode for Dye-Sensitized Solar Cells. J. Power Sources 2008, 181 (1), 172-176. https://doi.org/10.1016/j.jpowsour.2008.03.029.

(15) Zha, Z.; Yue, X.; Ren, Q.; Dai, Z. Uniform Polypyrrole Nanoparticles with High Photothermal Conversion Efficiency for Photothermal Ablation of Cancer Cells. Adv. Mater. 2013, 25 (5), 777-782. https://doi.org/10.1002/adma.201202211. 
(16) Kupila, E.-L.; Kankare, J. Influence of Electrode Pretreatment, Counter Anions and Additives on the Electropolymerization of Pyrrole in Aqueous Solutions. Synth. Met. 1995, 74 (3), 241-249. https://doi.org/10.1016/0379-6779(95)03369-U.

(17) MacDiarmid, A. G. Polyaniline and Polypyrrole: Where Are We Headed? Synth. Met. 1997, 84 (1), 27-34. https://doi.org/10.1016/S0379-6779(97)80658-3.

(18) Bereznev, S.; Kois, J.; Golovtsov, I.; Öpik, A.; Mellikov, E. Electrodeposited (Cu-In-Se)/Polypyrrole PV Structures. Thin Solid Films 2006, 511, 425-429. https://doi.org/10.1016/j.tsf.2005.11.074.

(19) Yuan, X.; Floresyona, D.; Aubert, P.-H.; Bui, T.-T.; Remita, S.; Ghosh, S.; Brisset, F.; Goubard, F.; Remita, H. Photocatalytic Degradation of Organic Pollutant with Polypyrrole Nanostructures under UV and Visible Light. Appl. Catal. B Environ. 2019, 242, 284-292.

https://doi.org/10.1016/j.apcatb.2018.10.002.

(20) Yuan, X.; Dragoe, D.; Beaunier, P.; Uribe, D. B.; Ramos, L.; Méndez-Medrano, M. G.; Remita, H. Polypyrrole Nanostructures Modified with Mono- And Bimetallic Nanoparticles for Photocatalytic $\mathrm{H}_{2}$ Generation. J. Mater. Chem. A 2019, 8 (1), 268-277. https://doi.org/10.1039/c9ta11088g.

(21) Wang, Y.; Liu, Y.; Xia, K.; Zhang, Y.; Yang, J. NiCo $\mathrm{S}_{4}$ Nanoparticles Anchoring on Polypyrrole Nanotubes for High-Performance Supercapacitor Electrodes. J. Electroanal. Chem. 2019, 840, 242-248. https://doi.org/10.1016/j.jelechem.2019.03.076.

(22) Wu, W.; Wei, D.; Zhu, J.; Niu, D.; Wang, F.; Wang, L.; Yang, L.; Yang, P.; Wang, C. Enhanced Electrochemical Performances of Organ-like $\mathrm{Ti}_{3} \mathrm{C}_{2}$ MXenes/Polypyrrole Composites as Supercapacitors Electrode Materials. Ceram. Int. 2019, 45 (6), 7328-7337. https://doi.org/10.1016/j.ceramint.2019.01.016.

(23) Yang, K.; Xu, H.; Cheng, L.; Sun, C.; Wang, J.; Liu, Z. In Vitro and In Vivo Near-Infrared Photothermal Therapy of Cancer Using Polypyrrole Organic Nanoparticles. Adv. Mater. 2012, 24 (41), 5586-5592. https://doi.org/10.1002/adma.201202625.

(24) Song, X.; Liang, C.; Gong, H.; Chen, Q.; Wang, C.; Liu, Z. Photosensitizer-Conjugated Albumin-Polypyrrole Nanoparticles for Imaging-Guided In Vivo Photodynamic/Photothermal Therapy. Small 2015, 11 (32), 3932-3941. https://doi.org/10.1002/smll.201500550.

(25) Shan, X.; Chen, Q.; Yin, X.; Jiang, C.; Li, T.; Wei, S.; Zhang, X.; Sun, G.; Liu, J.; Lu, L. Polypyrrole-Based Double Rare Earth Hybrid Nanoparticles for Multimodal Imaging and Photothermal Therapy. J. Mater. Chem. B 2020, 8 (3), 426-437. https://doi.org/10.1039/C9TB02254F.

(26) Su, C.; Zhong, H.; Chen, H.; Guo, Y.; Guo, Z.; Huang, D.; Zhang, W.; Wu, Q.; Yang, B.; Liu, Z. Black Phosphorus-Polypyrrole Nanocomposites for High-Performance Photothermal Cancer Therapy. New J. Chem. 2019, 43 (22), 8620-8626. https://doi.org/10.1039/C9NJ01249D.

(27) Au, K. M.; Lu, Z.; Matcher, S. J.; Armes, S. P. Polypyrrole Nanoparticles: A Potential Optical Coherence Tomography Contrast Agent for Cancer Imaging. Adv. Mater. 2011, 23 (48), 5792-5795. https://doi.org/10.1002/adma.201103190.

(28) Zha, Z.; Deng, Z.; Li, Y.; Li, C.; Wang, J.; Wang, S.; Qu, E.; Dai, Z. Biocompatible Polypyrrole Nanoparticles as a Novel Organic Photoacoustic Contrast Agent for Deep Tissue Imaging. Nanoscale 2013, 5 (10), 4462-4467. https://doi.org/10.1039/C3NR00627A. 
(29) Krug, P.; Kwiatkowska, M.; Mojzych, I.; Głowala, P.; Dorant, S.; Kępińska, D.; Chotkowski, M.; Janiszewska, K.; Stolarski, J.; Wiktorska, K.; Kaczyńska, K.; Mazur, M. Polypyrrole

Microcapsules Loaded with Gold Nanoparticles: Perspectives for Biomedical Imaging. Synth. Met. 2019, 248, 27-34. https://doi.org/10.1016/j.synthmet.2018.12.025.

(30) Qin, Z.; Wang, Y.; Randrianalisoa, J.; Raeesi, V.; Chan, W. C. W.; Lipinski, W.; Bischof, J. C. Quantitative Comparison of Photothermal Heat Generation between Gold Nanospheres and Nanorods. Sci. Rep. 2016, 6 (July), 1-13. https://doi.org/10.1038/srep29836.

(31) Shi, Z.; Zhou, Y.; Fan, T.; Lin, Y.; Zhang, H.; Mei, L. Inorganic Nano-Carriers Based Smart Drug Delivery Systems for Tumor Therapy. Smart Mater. Med. 2020, 1, 32-47. https://doi.org/10.1016/j.smaim.2020.05.002.

(32) Zhang, F.; Lu, G.; Wen, X.; Li, F.; Ji, X.; Li, Q.; Wu, M.; Cheng, Q.; Yu, Y.; Tang, J.; Mei, L. Magnetic Nanoparticles Coated with Polyphenols for Spatio-Temporally Controlled Cancer Photothermal/Immunotherapy. J. Control. Release 2020, 326, 131-139. https://doi.org/10.1016/j.jconrel.2020.06.015.

(33) Zeng, W.; Wu, X.; Chen, T.; Sun, S.; Shi, Z.; Liu, J.; Ji, X.; Zeng, X.; Guan, J.; Mei, L.; Wu, M. Renal-Clearable Ultrasmall Polypyrrole Nanoparticles with Size-Regulated Property for Second Near-Infrared Light-Mediated Photothermal Therapy. Adv. Funct. Mater. 2021, 31 (15), 1-11. https://doi.org/10.1002/adfm.202008362.

(34) Wen, P.; Tan, C.; Zhang, J.; Meng, F.; Jiang, L.; Sun, Y.; Chen, X. Chemically Tunable Photoresponse of Ultrathin Polypyrrole. Nanoscale 2017, 9 (23), 7760-7764. https://doi.org/10.1039/C6NR07143K.

(35) Amiri, M.; Alizadeh, N. Mid-Infrared Photoconductivity of Polypyrrole Doped with Cadmium Sulfide Quantum Dots. J. Phys. Chem. Solids 2020, 141, 109383.

https://doi.org/10.1016/j.jpcs.2020.109383.

(36) Yang, S.; Macharia, D. K.; Ahmed, S.; Zhu, B.; Zhong, Q.; Wang, H.; Chen, Z. Flexible and Reusable Non-Woven Fabric Photodetector Based on Polypyrrole/Crystal Violate Lactone for NIR Light Detection and Writing. Adv. Fiber Mater. 2020, 2 (3), 150-160. https://doi.org/10.1007/s42765-019-00022-X.

(37) Vishnuvardhan, T. K.; Kulkarni, V. R.; Basavaraja, C.; Raghavendra, S. C. Synthesis, Characterization and a.c. Conductivity of Polypyrrole/ $\mathrm{Y}_{2} \mathrm{O}_{3}$ Composites. Bull. Mater. Sci. 2006, 29 (1), 77-83. https://doi.org/10.1007/BF02709360.

(38) Fu, Y.; Manthiram, A. Core-Shell Structured Sulfur-Polypyrrole Composite Cathodes for Lithium-Sulfur Batteries. RSC Adv. 2012, 2 (14), 5927-5929. https://doi.org/10.1039/c2ra20393f.

(39) Guan, H.; Ding, T.; Zhou, W.; Wang, Z.; Zhang, J.; Cai, K. Hexagonal Polypyrrole Nanosheets from Interface Driven Heterogeneous Hybridization and Self-Assembly for Photothermal Cancer Treatment. Chem. Commun. 2019, 55 (30), 4359-4362. https://doi.org/10.1039/C9CC00809H.

(40) Bredas, J. L.; Scott, J. C.; Yakushi, K.; Street, G. B. Polarons and Bipolarons in Polypyrrole: Evolution of the Band Structure and Optical Spectrum upon Doping. Phys. Rev. B 1984, 30 (2), 1023-1025. https://doi.org/10.1103/PhysRevB.30.1023.

(41) Patil, A. O.; Heeger, A. J.; Wudl, F. Optical Properties of Conducting Polymers. Chem. Rev. 1988, 88 (1), 183-200. https://doi.org/10.1021/cr00083a009. 
(42) Siala, S.; Naydenkov, M.; Roucka, R.; Maros, A.; Gao, L.; Ding, D.; Suarez, F.; Dowd, P. Dilute Nitride Photodetector Arrays for Sensing Applications. In Proc.SPIE; 2020; Vol. 11276, p 112760H. https://doi.org/10.1117/12.2546295.

(43) Miyakawa, N.; Legner, W.; Ziemann, T.; Telitschkin, D.; Fecht, H.-J.; Friedberger, A. MEMS-Based Microthruster with Integrated Platinum Thin Film Resistance Temperature Detector (RTD), Heater Meander and Thermal Insulation for Operation up to $1,000^{\circ} \mathrm{C}$. Microsyst. Technol. 2012, 18 (7), 1077-1087. https://doi.org/10.1007/s00542-012-1441-0.

(44) Kumar, B.; Singh, S. V.; Chattopadhyay, A.; Biring, S.; Pal, B. N. Scalable Synthesis of a Sub-10 $\mathrm{Nm}$ Chalcopyrite $\left(\mathrm{CuFeS}_{2}\right)$ Nanocrystal by the Microwave-Assisted Synthesis Technique and Its Application in a Heavy-Metal-Free Broad-Band Photodetector. ACS Omega 2020, 5 (40), 25947-25953. https://doi.org/10.1021/acsomega.0c03336.

(45) Dou, L.; Yang, Y. M.; You, J.; Hong, Z.; Chang, W. H.; Li, G.; Yang, Y. Solution-Processed Hybrid Perovskite Photodetectors with High Detectivity. Nat. Commun. 2014, 5 (1), 1-6. https://doi.org/10.1038/ncomms6404.

(46) Tan, W. C.; Huang, L.; Ng, R. J.; Wang, L.; Hasan, D. M. N.; Duffin, T. J.; Kumar, K. S.; Nijhuis, C. A.; Lee, C.; Ang, K. W. A Black Phosphorus Carbide Infrared Phototransistor. Adv. Mater. 2018, 30 (6), 1-8. https://doi.org/10.1002/adma.201705039.

(47) Xu, K.; Zhou, W.; Ning, Z. Integrated Structure and Device Engineering for High Performance and Scalable Quantum Dot Infrared Photodetectors. Small 2020, 16 (47), 1-20. https://doi.org/10.1002/smll.202003397.

(48) Mukhokosi, E. P.; Manohar, G. V. S.; Nagao, T.; Krupanidhi, S. B.; Nanda, K. K. Device Architecture for Visible and Near-Infrared Photodetectors Based on Two-Dimensional $\mathrm{SnSe}_{2}$ and $\mathrm{MoS}_{2}$ : A Review. Micromachines 2020, 11 (8), 1-30. https://doi.org/10.3390/MI11080750. Pescaglini, A.; Martín, A.; Cammi, D.; Juska, G.; Ronning, C.; Pelucchi, E.; Iacopino, D. Hot-Electron Injection in Au Nanorod-ZnO Nanowire Hybrid Device for Near-Infrared Photodetection. Nano Lett. 2014, 14 (11), 6202-6209. https://doi.org/10.1021/nl5024854.

(50) Luo, L. B.; Zou, Y. F.; Ge, C. W.; Zheng, K.; Wang, D. D.; Lu, R.; Zhang, T. F.; Yu, Y. Q.; Guo, Z. Y. A Surface Plasmon Enhanced Near-Infrared Nanophotodetector. Adv. Opt. Mater. 2016, 4 (5), 763-771. https://doi.org/10.1002/adom.201500701.

(51) Hoang, C. V; Hayashi, K.; Ito, Y.; Gorai, N.; Allison, G.; Shi, X.; Sun, Q.; Cheng, Z.; Ueno, K.; Goda, K.; Misawa, H. Interplay of Hot Electrons from Localized and Propagating Plasmons. Nat. Commun. 2017, 8 (1), 771. https://doi.org/10.1038/s41467-017-00815-X.

(52) Zhao, X.; Duan, Y.; Li, K.; Fang, Y.; Song, X.; Zhang, H.; Yu, H. Au-PbS Core-Shell Nanorods for Plasmon-Enhanced near-Infrared Photodetection. J. Mater. Sci. 2019, 54 (24), 14720-14727. https://doi.org/10.1007/s10853-019-03920-y.

(53) Ye, X.; Zheng, C.; Chen, J.; Gao, Y.; Murray, C. B. Using Binary Surfactant Mixtures To Simultaneously Improve the Dimensional Tunability and Monodispersity in the Seeded Growth of Gold Nanorods. Nano Lett. 2013, 13 (2), 765-771. https://doi.org/10.1021/nl304478h. 
TOC figure:

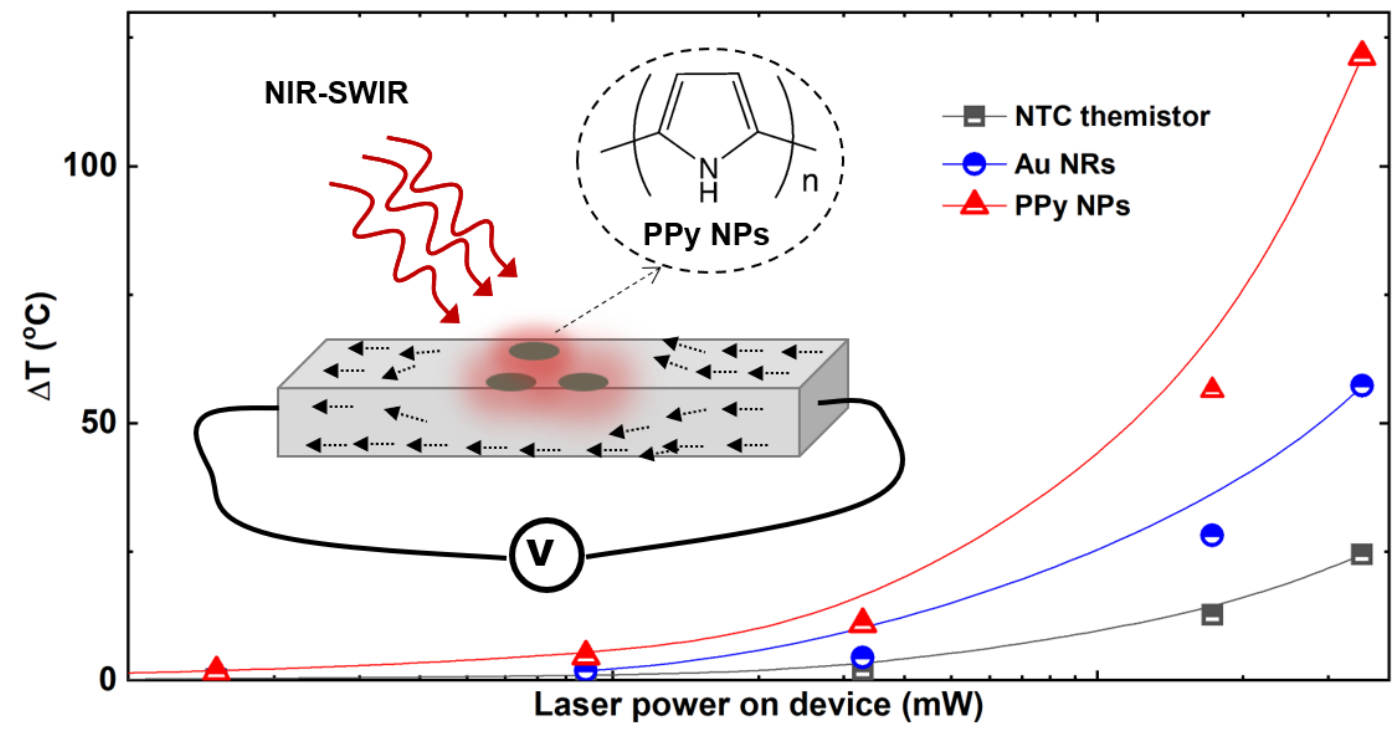

